Revista lus et Praxis, Año 24, No 3, 2018, pp. 309 - 334

ISSN 0717 - 2877

Universidad de Talca - Facultad de Ciencias Jurídicas y Sociales

Poderes normativos de la Corte Constitucional colombiana

Fabio Enrique Pulido Ortiz

Trabajo recibido el 28 de noviembre de 2017 y aprobado el 27 de julio de 2018

\title{
Poderes normativos de la Corte Constitucional colombiana*
}

\author{
Normative powers of the colombian Constitutional Court
}

Fabio Enrique Pulido Ortiz

\section{RESUMEN}

La doctrina o regla del precedente judicial supone que los jueces tienen el poder normativo de crear, modificar o derogar normas jurídicas. En ese contexto, el presente trabajo se propone explicar los tipos de poderes normativos que tiene la Corte Constitucional colombiana y, en consecuencia, señalar las clases de normas que crea este tribunal. Primero, se señala en qué sentido se puede afirmar que los jueces crean normas jurídicas y se precisan dos modelos al respecto: el modelo common law y el modelo legislativo. Luego se analizan los diferentes poderes normativos que ejerce la Corte Constitucional colombiana. La principal conclusión del trabajo es que las explicaciones que limitan el estudio del precedente a la noción de ratio decidendi tienen una insuficiente capacidad explicativa y justificativa.

\section{ABSTRACT}

The judicial precedent doctrine supposes that judges have the normative power to create, modify and derogate rules. This paper characterizes the different types of powers that the Colombian Constitutional Court exercises by examining the kinds of general and Abstract rules it makes. The work concludes that, while the Constitutional Court does indeed exercise several kinds of normative powers to create, modify and derogate rules that are both general and Abstract, any theoretical explanation of judicial precedent doctrine that merely limits its scope to ratio decidendi will necessarily be lacking in explanatory power and ultimately fail to provide the doctrine a sound justification.

\section{Palabras CLAVE}

precedente judicial, norma jurídica, Corte Constitucional, decisión judicial, ratio decidendi creación judicial del derecho, poderes normativos

\footnotetext{
* Este artículo se enmarca en el proyecto de investigación "Pretensión de normatividad del derecho en el razonamiento judicial. Un análisis en el marco de una práctica guiada por precedentes" (DER49-2016). Agradezco los comentarios y sugerencias de Luciano Laise, Alejandro Barreto, José Miguel Rueda, Ingrid Suarez Osma, Raquel Sarria, Valentina Guaba, Valentina González y de los participantes del seminario de investigación de la Maestría en Derecho Constitucional de la Universidad de La Sabana (2017). Por último, agradezco las sugerencias y los comentarios que recibí de evaluadores de este artículo que ayudaron a mejorarlo sustancialmente.

** Doctor en Derecho por la Universidad de Buenos Aires. Profesor de Teoría del Derecho y Derechos constitucionales. Director del Departamento de Teoría Jurídica y de la Constitución y de la Maestría en Derecho Constitucional de la Facultad de Derecho y Ciencias Políticas de la Universidad de La Sabana, Campus Universitario del Puente del Común, Km. 7 Autopista Norte de Bogotá, Chía, Cundinamarca, Colombia. E-mail: fabio.pulido@unisabana.edu.co ORCID No: orcid.org/0000-0002-1100-996.
} 
KEY WORDS

Judicial precedents, legal rules, Constitutional Court, judicial decisions, constitutional law

\section{Introducción}

En términos generales, los precedentes judiciales son normas generales (i.e. sus destinatarios son una categoría de personas) y abstractas (i.e. el objeto de regulación es una clase de acciones o estados de cosas) que provienen de las decisiones judiciales. Ahora bien, la obligatoriedad de los precedentes judiciales depende de que los ordenamientos jurídicos consagren o reconozcan la doctrina o regla de precedente vinculante ${ }^{1}$. El reconocimiento de esta regla implica admitir que los jueces (o por lo menos algunos de ellos) tienen la capacidad de crear normas jurídicas generales y abstractas. Por esta razón, uno de los aspectos centrales en la teoría del precedente es la explicación de los poderes normativos de los jueces de crear, modificar o derogar las normas jurídicas que constituyen los precedentes.

En la actualidad, no existe duda respecto de que el ordenamiento jurídico colombiano contempla una regla de precedente vinculante y que, en particular, las decisiones de la Corte Constitucional colombiana son una de sus fuentes ${ }^{2}$. Ahora bien, las discusiones jurisprudenciales y doctrinales sobre la doctrina de precedente, se han concentrado en cuestiones conceptuales, justificactorias y metodológicas relacionadas con la noción de ratio decidendi ${ }^{3}$. No obstante, si los poderes normativos de los jueces de crear normas generales y abstractas son más amplios que el del relacionado con la ratio decidenidi, entonces la

\footnotetext{
${ }^{1}$ Una revisión general de esta distinción puede verse en MACCORMick y Summers (1997), pp. 559-561; Cross y Harris (2012), pp. 48-49. En Pulido (2018) se explican con mayor detalle las cuestiones teóricas que se desarrollan en este artículo.

${ }^{2}$ Corte Constitucional, Sentencia C-335 de 2008, M.P: Humberto Sierra Porto, 16 de abril de 2008. Sobre la forma como se desarrolló y consolidó la regla de precedente en Colombia véase BERNAL Pulido, C. (2008), pp. 81-94; Quinche (2014), pp. 73-87; LóPez (2016), pp. 75-97 y LanCheros-Gámez (2012), pp. 159-186. No sobra advertir que la explicación de la regla de precedente es un asunto en el que se han involucrado la mayor parte de los ordenamientos jurídicos latinoamericanos. Véase, por ejemplo, Nogueira (2010), pp. 79-116; Garay (2013), pp. 193-250; Castillo (2016), pp. 15-42; Sagües (2006), pp. 17-32.

${ }_{3}^{3}$ Así, por ejemplo, el profesor Diego López Medina ha publicado dos influyentes trabajos sobre el tema en el que discute la justificación del precedente judicial y su adecuada reconstrucción, limitando la cuestión al problema de la ratio decidendi de las decisiones judiciales: López (2006), pp. 139-192; López (2016), pp. 27-75. En el mismo sentido, se ha analizado el concepto de "precedente" como "el conjunto de razones que expone un juez de una alta corte para sustentar la decisión judicial" y "que son tomadas por otro juez (otro operador jurídico) para aplicarlas a un nuevo caso, por la similitud de los "hechos". SierRa (2016), pp. 249-269.
} 
explicación de la regla de precedente depende de una teoría que logre comprender esos poderes.

Teniendo en cuenta esta problemática, el objetivo de este artículo es elucidar los poderes normativos que ejerce la Corte Constitucional colombiana y, en consecuencia, señalar las formas en que este tribunal crea normas generales y abstractas. Para ello, en la primera parte se explica en qué sentido se puede afirmar que los jueces crean normas jurídicas. En la segunda parte, se presentan dos modelos de creación judicial de normas generales y abstractas: el modelo common law y el modelo legislativo. En la tercera parte se analizan los diferentes poderes normativos que ejerce la Corte Constitucional colombiana. La principal conclusión del trabajo es que las explicaciones que limitan el estudio del precedente a la noción de ratio decidendi tienen una insuficiente capacidad explicativa y justificativa.

\section{Los poderes normativos de los jueces: la creación judicial del derecho}

Los poderes normativos se refieren a la capacidad que tienen los individuos de afectar las normas y deberes. En específico, los poderes normativos-jurídicos están constituidos por la competencia de algunos sujetos (típicamente las autoridades jurídicas) de cambiar (crear, modificar, regular o eliminar) las normas y deberes jurídicos existentes. Se supone que un acto normativo (i.e. el acto mediante el cual se ejerce un poder normativo) es válido si el sujeto tiene competencia para afectar los deberes y normas. Por ello, y en lo que se refiere a los actos normativos de las autoridades instituidas ( $v$. gr. el Congreso, el Presidente o las cortes de justicia), la validez del ejercicio de los poderes normativos depende de la existencia y alcance de las normas que les confieren poderes ${ }^{4}$.

La discusión acerca de si los jueces tienen el poder normativo de crear derecho ha sido de particular importancia en las discusiones teóricas y prácticas del último siglo ${ }^{5}$. Sin embargo, este problema se ha visto expuesto a la falta de claridad de su punto de partida. Siguiendo a Carrio, debe observarse que la pregunta acerca de si "los jueces crean derecho" es ambigua porque, en particular, el término "derecho" puede referirse a dos cosas: por un lado al "derecho" que tiene cada individuo sobre un bien, y, por el otro, al derecho entendido como el conjunto de normas positivas que conforman el ordenamiento jurídico ${ }^{6}$.

\footnotetext{
${ }^{4}$ Sobre el concepto de poderes normativos véase RAZ (1990), pp. 98-106; HART (1994), pp. 27-33; HOHFELD (1991), pp. 67-87.

${ }^{5}$ Una de las discusiones más conocidas sobre este asunto es el debate Hart-Dworkin: DwORKIN (1975), pp. 1057-1109 y HART (1994), pp. 238-276. Para una revisión crítica de este debate véase SHAPIRO and Ripstein (2007), pp. 22-55; AtRIA (2005).

6 CARRIÓ (1990), pp. 79-85.
} 
Teniendo en cuenta lo anterior, los siguientes párrafos se limitarán a explicar en qué sentido se puede afirmar que los jueces tienen el poder normativo de crear normas jurídicas positivas.

Los teóricos del derecho señalan la existencia de dos sentidos principales de norma jurídica: disposición jurídica, a saber el conjunto de símbolos lingüísticos expresados por una autoridad jurídica en un texto dotado de autoridad para la formulación de una norma; y norma jurídica en estricto sentido, esto es el contenido normativo formulado por las disposiciones jurídicas ${ }^{7}$. Se distingue también entre normas jurídicas generales y abstractas; y normas jurídicas individuales y concretas. La diferencia entre estos tipos de normas está en función de dos variables: los destinatarios de la norma y la caracterización de las propiedades que las conforman ${ }^{8}$. Las normas jurídicas son particulares cuando sus destinatarios son individuos específicos (es decir, personas específicas y determinadas) y son generales cuando sus destinatarios son una categoría de personas ( $v$. gr. ciudadanos colombianos, jueces etc.). Por otro lado, las normas jurídicas son abstractas cuando el objeto de regulación está conformado por clases de personas, acciones, objetos o estados de cosas ( $v$. gr. prohibido fumar en este salón de clases); y son concretas cuando la norma se refiere a personas, acciones, objetos o estados de cosas específicos que transcurren en un espacio y tiempo determinado 9 .

Las normas formuladas por las disposiciones constitucionales y legales son típicamente normas generales y abstractas. Cuando la Constitución Política colombiana prohíbe la censura previa lo hace respecto de todos los casos que califiquen como tal. Por otro lado, la parte resolutiva de las providencias judiciales son, en principio, un ejemplo de formulación de normas jurídicas individuales y $\operatorname{concretas}^{10}$. Cuando un juez ordena al Comité de Clasificación de

\footnotetext{
7 Sobre estas distinciones, véase: Rodríguez (2003), pp. 87-109; NAvarro y RodríGuez (2014), pp. 79-81. Debe tenerse en cuenta que es posible diferenciar dos tipos de contenidos normativos. Por un lado -siguiendo la terminología de Hart- las normas primarias definen si determinada acción es obligatoria, prohibida o facultativa. Por otro lado, las normas secundarias otorgan potestades públicas o privadas para crear, modificar o derogar normas; HART (1994), pp. 27-33.

${ }^{8}$ Esta distinción fue trazada por Hans Kelsen al sostener que "Un tribunal, en especial, un tribunal de última instancia, puede estar facultado no solo para producir con sus sentencias normas obligatoria individuales, válidas para el caso presente, sino también normas generales. Así pasa cuando la sentencia judicial crea un Ilamado precedente"; KeLSEN (1982), p. 258. Sin embargo, Bulygin sostiene que afirmar que las sentencias judiciales son normas individuales es una exageración porque el concepto de norma exige generalidad por lo menos en relación del destinatario de la norma; BuLYGIN (2003), pp. 7-25.

${ }^{9}$ Alchourrón y Bulygin (1987), pp. 58-61.

${ }^{10}$ Debe resaltarse que no es posible generalizar la tesis según la cual los decisum de las sentencias son normas individuales y concretas. Por una lado porque es posible la existencia de una sentencia judicial en cuya parte resolutiva no se ejerza poder normativo alguno ( $v$. gr. una sentencia inhibitoria). Además
} 
Películas que permita la presentación de una película específica, el decisum (es decir la resolución del caso en la providencia) se refiere a este caso particular y de acuerdo a los hechos que lo suscitaron.

Teniendo en cuenta estas precisiones, veamos ahora en qué sentido se puede afirmar que los jueces, mediante sus sentencias, tienen el poder normativo de crear normas jurídicas generales y abstractas. Las sentencias judiciales son actos normativos complejos integrados por distintos tipos de normas, argumentos jurídicos y argumentos fácticos. Como se sabe, las sentencias están conformadas por tres partes principales: los antecedentes, la parte considerativa y la parte resolutiva (o decisum). En los antecedentes se suelen describir los hechos configurativos del problema jurídico a resolver y los actos procesales previos a la decisión. La parte considerativa se conforma de los argumentos y resultados interpretativos expuestos por el juez para justificar la decisión. Por último, en la parte resolutiva se define la solución del problema jurídico ${ }^{11}$.

En este contexto, se suele afirmar que la creación judicial de normas generales y abstractas se asocia a la carga de justificación de las providencias (esto significa que, en principio, la creación judicial del derecho depende de los argumentos de la parte considerativa de las sentencias). Se supone que, en virtud del principio de legalidad, los jueces están obligados a articular las razones jurídicas en las que se basan para formular la decisión del caso. Por ello, el proceso de toma de decisiones requiere como condición necesaria el uso de una premisa general que sirva de fundamento a la conclusión ${ }^{12}$. En general se espera que esa premisa corresponda al derecho existente. Pero cuando el derecho resulta indeterminado respecto a un asunto específico, el juez debe definir el contenido que sirve de fundamento a su decisión. Es por este motivo que se afirma que los jueces crean derecho cuando las normas generales con la que justifican sus sentencias no coinciden con el derecho vigente al momento de la decisión ${ }^{13}$.

Antes de continuar en el desarrollo de la exposición es necesario precisar cuatro asuntos. 1) Afirmar que los jueces construyen o crean normas jurídicas, no significa que creen tales normas ex nihilo (i.e. una creación normativa "desde la nada"). En realidad, cuando los jueces crean normas

porque -como se verá más adelante- existen decisiones judiciales cuya parte resolutiva es general y abstracta ( $v$. gr. la decisión sobre la constitucionalidad abstracta de una norma).

${ }^{11}$ Carrió (1990), pp. 81-89; Bulygin (2005), pp. 29-44; Aguiló (2015), pp. 1049-1051.

12 Bulygin (2003), p. 13.

13 Bulygin (2005), pp. 29-44. 
jurídicas para resolver, por ejemplo, casos sobre los cuales no existe regulación jurídica alguna, recurren a diferentes técnicas como identificar principios morales que justifican una práctica jurídica específica o extender la aplicación de normas a cuestiones no reguladas en ellas.

2) En el discurso jurídico suele hablarse de actividades 'interpretativas' en relación con respuestas que van desde la identificación del significado lingüístico de las disposiciones jurídicas, hasta la definición de contenidos originales necesarios para dar una respuesta judicial a un caso. Para reducir la vaguedad en la descripción de las actividades interpretativas, resulta aconsejable diferenciar entre: a) la determinación del significado, b) la interpretación stricto sensu y c) 'interpretación lato sensu. La determinación del significado de las disposiciones jurídicas se refiere a la actividad tendiente a comprender el contenido normativo formulado en los textos jurídicos. La 'interpretación stricto sensu' corresponde a la actividad de asignar significado en los casos en que existen dudas sobre éste. La 'interpretación lato sensu' a la creación de normas, con independencia del significado de las disposiciones jurídicas existentes (por ejemplo cuando existe una laguna jurídica o cuando simplemente los jueces deciden apartarse del derecho vigente), como resultado, por ejemplo, de la evaluación de las razones que justifican una práctica jurídica.

3) Afirmar que los jueces crean normas jurídicas generales y abstractas como presupuesto de la justificación de sus decisiones judiciales, no significa, necesariamente, que tales normas vinculen en casos posteriores, pues para que esto ocurra, el ordenamiento jurídico debe reconocer una regla o doctrina de precedente que exija que casos posteriores se resuelvan según las normas jurídicas creadas por los jueces en casos precedentes.

4) Aun cuando es cierto que una de las principales fuentes de creación judicial de normas jurídicas, es la relativa a la necesaria justificación de sus decisiones, esto es que, como se ha dicho, en los casos en que por alguna razón, el derecho vigente es insuficiente para dar respuesta a los problemas jurídicos, los jueces construyen esas premisas que empelan como premisa justificatoria de sus decisiones. Es verdad también que el concepto de ratio decidendi se ha desarrollado para referirse a las normas que los jueces construyen con esos propósitos. Sin embargo, en los ordenamientos jurídicos actuales los jueces crean normas jurídicas generales y abstractas en un contexto más amplio del que se pretende captar con esa noción. Por ejemplo -y como se mostrará más adelante en este artículo- la Corte Constitucional colombiana crea normas generales y abstractas mediante diversos mecanismos que exceden la noción de ratio decidendi.

\section{Los modelos de creación judicial del derecho}

Existe una discusión abierta acerca de la adecuada caracterización y justificación del poder normativo de los jueces de crear normas jurídicas generales 
y abstractas. Al respecto, Komarek sostiene que es posible señalar la existencia de dos modelos: el modelo "common law" y el modelo "legislativo"14.

El modelo "common law" parte del supuesto de que la creación judicial de normas jurídicas generales y abstractas es un producto de la lenta y constante revisión de los hechos normativos en cada proceso judicial. Según este modelo, las normas jurídicas de origen judicial dependen de la definición judicial de problemas jurídicos concretos de la vida real y no de la abstracción y generalización de contenidos normativos hipotéticos ${ }^{15}$. Por el contrario, el modelo "legislativo" sostiene que la creación judicial del derecho funciona de forma similar a la creación legislativa de normas. De acuerdo con este modelo, los jueces (en particular los órganos de cierre) suelen crear normas de contenido general y abstracto que regulan casos genéricos que no se vinculan necesariamente con los hechos resueltos en la sentencia judicial (esto es, en otras palabras, realización de formulaciones normativas mediante una abstracción y generalización de casos hipotéticos) ${ }^{16}$.

Estos modelos de creación judicial de normas jurídicas tienen en mente dos visiones distintas de la autoridad judicial ( $y$, en consecuencia, dos formas distintas de justificar la creación judicial del derecho). El modelo del "common law" se basa en la autoridad judicial de crear normas jurídicas generales y abstractas como consecuencia de la experiencia compartida de la resolución de situaciones jurídicas reales y concretas ${ }^{17}$. Los precedentes, según esta idea, son comprendidos como una representación de la "sabiduría" acumulada en la resolución de casos. Por otro lado, el modelo "legislativo" fundamenta la creación judicial del derecho en un ideal de autoridad jerárquica, de acuerdo con el cual las decisiones acerca del contenido del derecho efectuadas por los órganos de cierre de las jurisdicciones ( $v$. gr. cortes supremas y los tribunales constitucionales) son vistos como pronunciamientos autoritativos acerca del contenido del derecho vigente, que vincula a los operadores jurídicos con independencia de los hechos del caso que llevaron a la decisión.

Pero hay otra diferencia entre estos modelos que aquí interesa remarcar. El modelo common law entiende que las normas que constituyen los precedentes no dependen de los términos empleados por el juez en los textos de las decisiones judiciales. Según esto, la identificación de los precedentes judiciales depende

\footnotetext{
14 Komarek (2013), pp. 149-171.

${ }^{15}$ Una descripción adicional de este modelo puede verse en LeVI (1948), pp. 501-574; CuEto (1997), pp. 147-196.

16 Komarek (2013), pp. 149-171.

17 Komarek (2013), p. 163-165. Sobre este punto en el derecho constitucional norteamericano véase también MAGALONI (2001), pp. 1-28.
} 
de la forma cómo en efecto se resuelven los casos, y no de las palabras que emplean los jueces o tribunales con la intención de crear reglas. Por el contrario, para el modelo legislativo los precedentes judiciales son formulados a través de las formulas lingüísticas empleadas por los jueces con la intención de crear normas generales y abstractas ${ }^{18}$. Como se ve, los precedentes judiciales son, en este caso, formulados mediante un texto de manera similar a como opera la formulación legislativa del derecho.

Debe advertirse que estos modelos de creación judicial del derecho no pretenden ser descriptivos de los ordenamientos jurídicos actuales, sino que buscan representar ideales regulativos y explicativos. Muestra de ello es que en algunos países de la tradición jurídica del common law se han desarrollado prácticas que, en principio, son contrarias al modelo. En el derecho constitucional estadounidense se ha observado una "textualización"19 del precedente, por cuanto los jueces y abogados basan la actividad de identificación de los precedentes en las formulaciones lingüísticas de los precedentes. Incluso, dentro de una misma práctica jurídica pueden convivir diferentes formas de creación judicial del derecho. Por ejemplo -y sin pretender responder al asunto de forma definitiva- la ratio decidendi en el derecho constitucional colombiano constituye una mezcla de los dos modelos. En la sentencia SU-230 de 2015, la Corte Constitucional sostiene la existencia de dos tipos de ratio decidendi: de acuerdo con el primero, las reglas creadas por la Sala Plena de la Corte Constitucional, mediante las cuales justifica determinadas decisiones, son constitutivas de ratio decidendi; y de acuerdo con el segundo, al cual denomina jurisprudencia en vigor, la reiteración de decisiones en torno a un punto específico de derecho tiene la capacidad de generar una ratio decidendi vinculante ${ }^{20}$.

En síntesis, el modelo common law sostiene que la creación judicial del derecho es el producto de una lenta y constante revisión de los hechos normativos, mientras que el modelo legislativo entiende que la creación de normas generales y abstractas se hace por medio de la formulación hipotética de contenidos normativos novedosos. El modelo "common law" entiende la autoridad judicial concebida como consecuencia de la experiencia compartida de la resolución de problemas jurídicos de la vida real. El modelo "legislativo", por el contrario, concibe un ideal jerárquico de la autoridad judicial en el que el derecho creado

\footnotetext{
18 Komarek (2013), p. 165.

${ }^{19}$ Komarek hace referencia a un trabajo de Tiersma (2013), donde se sostiene que en Estados Unidos el common law se ha dirigido, de manera paulatina, hacia una textualización, por cuanto el derecho judicial es, cada vez más, aquello que los jueces escriben en sus providencias, antes que los hechos relevantes y los principios subyacentes.

${ }^{20}$ Corte Constitucional, Sentencia SU-230 de 2015, M.P. Jorge Ignacio Pretelt, 29 de abril de 2015.
} 
por los jueces (en especial por las altas cortes) es visto como un conjunto de normas jurídicas desvinculadas de los hechos de los casos resueltos (véase tabla 1).

Tabla 1: modelos de creación judicial del derecho

\begin{tabular}{|l|l|}
\hline \multicolumn{1}{|c|}{ Modelo common law } & \multicolumn{1}{c|}{ Modelo legislativo } \\
\hline $\begin{array}{l}\text { Las normas jurídicas generales y abs- } \\
\text { tractas de origen judicial son producto } \\
\text { de una lenta y constante revisión de los } \\
\text { hechos normativos en cada proceso y } \\
\text { providencia. }\end{array}$ & $\begin{array}{l}\text { El derecho judicial es creado mediante } \\
\text { actos de legislación, esto es, mediante la } \\
\text { formulación expresa de normas_en el len- } \\
\text { guaje de las disposiciones jurídicas. }\end{array}$ \\
\hline $\begin{array}{l}\text { Las normas jurídicas de origen judicial } \\
\text { se justifican en virtud de su estrecha re- } \\
\text { lación con las situaciones concretas de } \\
\text { la vida real que son llevadas para que } \\
\text { sean resueltas por los jueces. }\end{array}$ & $\begin{array}{l}\text { Los jueces (en particular los órganos de } \\
\text { cierre) suelen crear normas de conteni- } \\
\text { do general que regulan casos genéricos, } \\
\text { los cuales no se vinculan necesariamente } \\
\text { con los hechos resueltos en la sentencia } \\
\text { judicial. }\end{array}$ \\
\hline $\begin{array}{l}\text { La justificación de la creación judicial } \\
\text { del derecho se basa en la sabiduría } \\
\text { acumulada en la resolución de casos } \\
\text { jurídicos. }\end{array}$ & $\begin{array}{l}\text { La justificación de la creación judicial del } \\
\text { derecho se fundamenta en un ideal jerár- } \\
\text { quico de la autoridad judicial. }\end{array}$ \\
\hline
\end{tabular}

\section{Poderes normativos de la Corte Constitucional}

En los sistemas jurídicos que reconocen una doctrina del precedente vinculante, los jueces -a través de sus providencias judiciales- ejercen, al menos, dos poderes normativos: 1) resolver de forma autoritativa los problemas jurídicos que les son planteados, y 2) ser fuente de normas jurídicas generales y abstractas que regulan casos más allá de lo decidido en el fallo respectivo. La cosa juzgada, esto es, la fuerza normativa de la decisión judicial sobre los problemas específicos planteados a los jueces, se refiere a la primera función; y el precedente judicial, es decir, las reglas jurídicas generales originadas en las decisiones judiciales, a la segunda función.

La diferencia entre la cosa juzgada y el precedente judicial radica, en principio, en su fuerza normativa. La fuerza normativa de la cosa juzgada se limita a la resolución del caso o problema resuelto en la providencia por el juez. La fuerza normativa del precedente, por el contrario, trasciende de forma necesaria de la resolución de la litis, pues tiene la capacidad de constituirse en norma para las decisiones de los operadores jurídicos en casos futuros. Esta diferencia se puede observar en el siguiente ejemplo. Un colegio decidió expulsar a Luisa, una estudiante de noveno grado como consecuencia de su estado de embarazo. Luego del proceso de amparo de los derechos constitucionales de Luisa, la 
Corte Constitucional definió que: a) esa decisión resulta inconstitucional y, en consecuencia, ordenó su reintegro al colegio. Según la Corte Constitucional, b) la expulsión de una estudiante por ese motivo está prohibida por ser discriminatoria y violatoria del derecho a la educación. El argumento a) corresponde a la cosa juzgada de la providencia cuya su fuerza normativa se limita a la situación de Luisa y el Colegio que la expulsó. En cambio, el argumento b) se refiere al precedente judicial que (en virtud de la doctrina del precedente vinculante) tiene la capacidad de regular todos los casos que correspondan a la formulación de esa regla ${ }^{21}$.

Sin embargo, la diferenciación entre cosa juzgada y precedente no es tan sencilla cuando dentro de las competencia de los jueces se incluye la de resolver problemas jurídicos abstractos (por ejemplo, la definición en abstracto de la constitucionalidad de normas), y al mismo tiempo se establece que esas decisiones judiciales tienen efectos erga omnes (expresión latina que significa respecto de todos o frente a todos). Este es el caso de las competencias de la Corte Constitucional colombiana. La constitución colombiana encargó a la Corte Constitucional dos competencias: (1) el control abstracto de constitucionalidad de normas con rango de ley y de las reformas constitucionales, y (2) el control concreto mediante la revisión de las decisiones judiciales relacionadas con la acción de tutela de los derechos constitucionales ${ }^{22}$. Así, mediante la competencia (1) las providencias de Corte Constitucional resuelven problemas generales y abstractos (mediante sentencias tipo " $\mathrm{C}$ "), mientras que la competencia (2) resuelve problemas jurídicos particulares y concretos (a través de las sentencias tipo "T" $\mathrm{y}$ "SU"23). Veamos, por tanto, la forma como la Corte Constitucional colombiana ejerce sus poderes normativos en el desarrollo de esas competencias.

\subsection{Poderes normativos de la Corte Constitucional en ejercicio del control constitucional abstracto}

En el caso de las sentencias C, los dispositivos establecidos en el decisum tienen efectos generales y abstractos (efectos erga omnes). El artículo 243

\footnotetext{
${ }^{21}$ Este precedente judicial puede verse en Sentencia T-290 de 1996, M.P.: Jorge Arango Mejía, 28 de junio de 1996.

22 Constitución Política de Colombia, artículos 86 y 241.

${ }^{23}$ En lo referente a la nomenclatura de sus sentencias, la Corte Constitucional identifica las sentencias de constitucionalidad abstracta con la letra $C$, seguida del número de la sentencia y el año de la misma; por su parte, las sentencias de tutela las identifica con las letras T o SU (sentencias de unificación), seguidas por el número de la sentencia y el año. La diferencia fundamental entre las sentencias T y las SU es que las segundas son dictadas por la Sala Plena de la Corporación, mientras que las primeras son dictadas por salas de revisión (tres magistrados).
} 
de la Constitución establece que "Ios fallos que la Corte dicte en ejercicio del control jurisdiccional hacen tránsito a cosa juzgada constitucional". El mismo artículo define que "ninguna autoridad podrá reproducir el contenido material del acto jurídico declarado inexequible ${ }^{24}$ por razones de fondo, mientras subsistan en la Carta las disposiciones que sirvieron para hacer la confrontación entre la norma ordinaria y la Constitución". Como consecuencia de la cosa juzgada constitucionalidad, y de sus efectos erga omnes, surgen dos escenarios:

En el primer escenario, cuando la Corte Constitucional declara la inconstitucionalidad, la cosa juzgada implica la inexequibilidad de la norma (i.e. su expulsión del ordenamiento jurídico) y la imposibilidad de aplicar nuevamente la norma declarada inexequible ${ }^{25}$. Así, por ejemplo, cuando la Corte Constitucional declaró la inexequibilidad del artículo 162 de la Ley № 1.801 de 2016, que autorizaba a las autoridades administrativas (en específico a los alcaldes municipales) para ordenar registros de domicilios, en consecuencia esa norma fue derogada (i.e. expulsada del ordenamiento jurídico colombiano) y, a partir de ese momento quedo prohibida su aplicación ${ }^{26}$.

En el segundo escenario, es decir cuando la Corte Constitucional declara la constitucionalidad, la consecuencia de la cosa juzgada es que la norma se conserve en el ordenamiento jurídico y que la norma no pueda ser demandada nuevamente ${ }^{27}$. Así, por ejemplo, en 1994, la Corte Constitucional

${ }^{24}$ En el derecho colombiano se entiende por exequibilidad el efecto de las decisiones de la Corte Constitucional que declaran la constitucionalidad de las normas y que, por tanto, se conservan en el ordenamiento jurídico. Por lo mismo, una decisión de inconstitucionalidad tiene como efecto la inexequibilidad de la norma, esto es, su expulsión del ordenamiento jurídico.

${ }^{25}$ La Corte Constitucional ha reconocido excepciones a esta regla mediante la doctrina de la inconstitucionalidad diferida. Según la Corte, "una sentencia de inconstitucionalidad diferida, o de constitucionalidad temporal, es aquella por medio de la cual el juez constitucional constata que la ley sometida a control es inconstitucional, pero decide no retirarla inmediatamente del ordenamiento, por la sencilla razón de que la expulsión automática de la disposición ocasionaría 'una situación peor, desde el punto de vista de los principios y valores constitucionales', por lo cual el Tribunal Constitucional establece un plazo prudencial para que el Legislador corrija la inconstitucionalidad que ha sido constatada". Corte Constitucional, Sentencia C-737 de 2001, M.P. Eduardo Montealegre Lynett, 11 de julio de 2001. Por ejemplo, en la sentencia C-149 de 1993 (M.P. José Gregorio Hernández, 22 de abril de 1993), la Corte declaró la inconstitucionalidad de un impuesto y ordenó conferir efectos retroactivos la decisión. Por otro lado, en la sentencia C-737 de 2001 (M.P. Eduardo Montealegre, 11 de julio de 2001), la Corte aplazó los efectos de la declaratoria de inexequibilidad de un decreto del Gobierno proferido en un estado de excepción.

${ }^{26}$ Véase Corte Constitucional, Sentencia C-223 de 2017, M.P. Alberto Rojas, 20 de abril de 2017.

${ }^{27}$ Esta idea ha sido matizada por la Corte Constitucional, en el marco de la doctrina de la cosa juzgada constitucional, que se refiere al "carácter inmutable de las sentencias de la Corte Constitucional". Sin embargo, la Corte establece una diferencia entre la cosa juzgada constitucional absoluta y la relativa: 
declaró la constitucionalidad del artículo 10 de la Ley Nº 48 de 1993 que consagra el deber de "todo varón... a definir su situación militar a partir de la fecha en que cumpla su mayoría de edad". El argumento central de la Corte Constitucional era que esa obligación no violaba la igualdad entre hombres y mujeres. Posteriormente, esa norma fue demandada (otra vez por una supuesta violación al derecho a la igualdad) y la Corte Constitucional, en aplicación del principio de cosa juzgada constitucional, decidió que resultaba improcedente pronunciarse nuevamente ${ }^{28}$.

Según esto, la diferenciación entre precedente y cosa juzgada basada en la existencia de normas generales y abstractas (para los precedentes) y normas individuales y concretas (para la cosa juzgada), es insuficiente para dar cuenta de los ordenamientos jurídicos que cuenten con control constitucional abstracto. Como se explicó, en estos ordenamientos jurídicos -como el colombiano- las providencias judiciales pueden tener efectos de cosa juzgada erga omnes, esto es que sus efectos normativos son generales y abstractos.

Un elemento adicional que complejiza la diferenciación entre la cosa juzgada y precedentes judiciales (basada en sus efectos normativos) son los condicionamientos de las sentencias de constitucionalidad abstracta ${ }^{29}$. Por lo general, se espera que el fallo de estas sentencias concluya si la norma jurídica es constitucional (y por lo tanto exequible) o inconstitucional (y por lo tanto inexequible). Sin embargo, los tribunales constitucionales ofrecen respuestas "condicionadas" ${ }^{30}$. Estos tribunales, en vez de declarar que una norma jurídica $X$ es constitucional o inconstitucional, definen que esa norma $X$ es constitu-

la cosa juzgada es absoluta "cuando el pronunciamiento de constitucionalidad de una disposición, a través del control abstracto, no se encuentra limitado por la propia sentencia"; y es relativa "cuando el juez constitucional limita en forma expresa los efectos de la decisión, dejando abierta la posibilidad para que en un futuro se formulen nuevos cargos de inconstitucionalidad". Corte Constitucional, Sentencia C-332 de 2013, M.P. Mauricio González Cuervo, 5 de junio de 2013.

${ }^{28}$ Corte Constitucional, Sentencia C-007 de 2016, M.P. Alejandro Linares, 21 de enero de 2016. La Corte Constitucional suele diferenciar entre cosa juzgada formal "cuando existe una decisión previa del juez constitucional en relación con la misma norma que es objeto de una nueva demanda, o cuando una nueva norma con un texto exactamente igual a uno anteriormente examinado por la Corte, es nuevamente demandado por los mismos cargos" y cosa juzgada material "cuando la disposición demandada reproduce el mismo sentido normativo de otra norma que ya fue examinada por la Corte". Corte Constitucional, Sentencia C-393 de 2011, M.P. María Victoria Calle, 18 de mayo de 2011.

${ }^{29}$ Sobre esta práctica, véase, para el derecho constitucional español: Díaz Revorıo (2000), pp. 17991824, y para el colombiano, Olano (2004), pp. 571-602.

${ }^{30}$ En estos casos, según la Corte Constitucional, es posible señalar diferentes resultados interpretativos de la disposición jurídica analizada, es decir, que si ésta "admite varias interpretaciones, de las cuales algunas violan la Carta pero otras se adecuan a ella, entonces corresponde a la Corte proferir una constitucionalidad condicionada o sentencia interpretativa que establezca cuáles sentidos de la disposición acusada se mantienen dentro del ordenamiento jurídico y cuáles no son legítimos 
cional sí y sólo sí se entiende que debe contemplar el contenido normativo $\mathrm{Y}^{31}$. Este es el caso, por ejemplo, si la Corte Constitucional en vez de declarar la exequibilidad de la norma que establece el deber de todo varón de definir su situación militar, agrega que es constitucional sí y sólo sí se entiende que las mujeres pueden prestar el servicio militar libremente ${ }^{32}$.

En este contexto, cuando los tribunales constitucionales condicionan sus sentencias, el contenido del decisum excede a la declaración de exequibilidad o inexequibilidad de una norma. En otras palabras, en las sentencias condicionadas se definen o incorporan contenidos normativos adicionales que resultan exigibles de forma general y abstracta en casos futuros ${ }^{33}$. Por esa razón, en las sentencias que realizan condicionamientos -como la del ejemplo- resulta problemático diferenciar entre cosa juzgada (entendida como los efectos específicos de la providencia judicial) y el precedente constitucional (entendido como la norma jurídica general y abstracta que se deriva de esa providencia judicial $)^{34}$.

Pero lo que resulta más importante para los propósitos de este trabajo, es subrayar que en relación con la cosa juzgada constitucional de las sentencias de constitucionalidad abstracta, la Corte Constitucional ejerce dos tipos de poderes normativos (todos de contenido general y abstracto): 1) la definición de constitucionalidad o inconstitucionalidad de una norma con efectos erga omnes; y 2) la definición de constitucionalidad condicionada de una norma con efectos erga omnes.

constitucionalmente" (Corte Constitucional, Sentencia C-259 de 2015, M.P. Gloria Stella Ortiz Delgado, 6 de mayo de 2015).

${ }^{31}$ Entre estas decisiones, se pueden diferenciar las que "eligen" el significado de las reglas jurídicas, según este se ajuste a la constitución, de las que lo "manipulan", es decir, las decisiones que transforman el significado de las reglas jurídicas, bajo el argumento de compatibilizar el contenido de la ley con la constitución; Olano (2004), pp. 571-602.

${ }^{32}$ Esto fue lo que hizo la Corte Constitucional en la Sentencia C-007 de 2016, M.P. Alejandro Linares, 21 de enero de 2016.

${ }^{33}$ En relación con las sentencias condicionadas es posible diferenciar entre la definición de constitucionalidad condicionada simple (i.e. definiendo un sentido de la norma que se considera constitucional o defendiendo cuales sentidos se consideran inconstitucionales) de una norma y la definición de constitucionalidad condicionada ampliada (i.e. definiendo contenidos normativos adicionales que condicionan la constitucionalidad) de una norma.

${ }^{34}$ Esta diferenciación corresponde, como veremos, a la que existe entre ratio decidendi y parte resolutiva. Véase las sentencias: Corte Constitucional, C-037 de 1996, M.P. Vladimiro Naranjo Mesa, 5 de febrero de 1996; C-774 de 2001, M.P. Rodrigo Escobar Gil, 25 de julio de 2001, y C-028 de 2006, M.P. Humberto Antonio Sierra Porto, 26 de enero de 2006. 


\subsection{Poderes normativos de la Corte Constitucional en ejercicio del control constitucional concreto}

En las sentencias de la Corte Constitucional que resuelven los casos de revisión de decisiones de tutela (sentencias T y $\mathrm{SU}$ ) sus dispositivos son, por regla general, inter-partes, y excepcionalmente inter-comunis. Los efectos de la parte resolutiva de estas sentencias son inter-partes cuando vinculan exclusivamente a las partes del proceso. Los efectos son inter-comunis cuando vinculan a quienes fueron parte del proceso y a quienes fueron parte del problema jurídico que originó la sentencia, pero que no hicieron parte del proceso ${ }^{35}$. Un ejemplo de efectos inter-partes es el mencionado antes sobre la situación de Luisa quien fue expulsada de su colegio por encontrarse en estado de embarazo. El decisum es inter-partes en tanto sólo vincula a Luisa y al colegio. Por otro lado, como ejemplo de efectos inter-comunis, imaginemos el caso de Pedro y Marcos quienes estando recluidos en un centro carcelario solicitan que se realicen las obras necesarias para adecuar los baños a estándares mínimos de salubridad. En el evento en que el fallo de tutela decida proteger los derechos de los demandantes, al definir la resolución del caso, se debe tener en cuenta que sus efectos afectarán la situación de los reclusos que no hicieron parte del proceso.

En estas situaciones no es sencillo definir si esa norma (i.e. la relativa a los efectos inter comunis) es general/abstracta o individual/concreta. Si la norma define la situación de un grupo determinado de sujetos y regula la acción u omisión específica de un sujeto o autoridad (como el ejemplo de la cárcel) entonces la norma es individual (sólo se refiere a un grupo de individuos específicos) y concreta (se limita a regular una acción específica). Si, por el contrario, la norma define la situación de una clase de personas ( $v$. gr. los trabajadores o los estudiantes de la universidad) y regula una clase de acciones ( $v$. gr. los despidos o las expulsiones), entonces la norma es general y abstracta.

La Corte Constitucional ha sostenido que en los casos de declaración de excepción de inconstitucionalidad en sentencias de tutela, la parte resolutiva de

\footnotetext{
${ }^{35}$ Véase Corte Constitucional, Auto 207/10, M.P. Luis Ernesto Vargas, 30 de junio de 2010. Sentencias T-583 de 2006, M.P. Marco Gerardo Monroy, 26 de julio de 2006 y SU913-09, M.P. Juan Carlos Henao, 11 de diciembre de 2009. En palabras de la Corte Constitucional, existen situaciones en las que la protección "de los derechos fundamentales de los accionantes debe hacerse extensiva a otras personas o ciudadanos que no han acudido a la acción de tutela, o que habiendo acudido, no son demandantes dentro de los casos bajo estudio, pero que sin embargo se encuentran en situaciones de hecho o de derecho similares o análogas a las de los actores". En estas circunstancias, para que el dispositivo de la sentencia tenga efectos inter comunis debe darse que las personas "se encuentren en condiciones comunes, similares o análogas a las de quienes sí hicieron uso de la acción de tutela" y que "cuando la orden de protección dada por el juez de tutela repercuta, de manera directa e inmediata, en la vulneración de derechos fundamentales de aquellos no tutelantes" (Auto 207/10, M.P. Luis Ernesto Vargas, 30 de junio de 2010).
} 
los fallos puede ser inter pares. Según la Corte Constitucional, la inaplicación de una norma por excepción de inconstitucionalidad puede tener efectos inter pares cuando: a) "la excepción de inconstitucionalidad resulte de la simple comparación de la norma inferior con la Constitución" ; b) "la norma constitucional violada, según la interpretación sentada por la Corte Constitucional, defina de manera clara la regla jurídica que debe ser aplicada"; c) "la inconstitucionalidad pueda ser apreciada claramente, sin que sea necesario sopesar los hechos particulares del caso y, por lo tanto, la inconstitucionalidad no dependa de tales hechos" d) la norma inaplicada trate materias sobre las cuales la Corte Constitucional tiene competencia (v. gr. normas que regulan derechos humanos); y e) "la decisión haya sido adoptada por la Sala Plena de la Corte en cumplimiento de su función de unificar la jurisprudencia o haya sido reiterada por ella" ${ }^{\prime 36}$ (esto último significa que sólo las sentencias SU tienen efectos inter pares). En estos casos, la norma del dispositivo de la sentencia inter pares es general y abstracta en tanto que, como se ha dicho a lo largo de este trabajo, define la situación de una clase de sujetos y regula clases de acciones.

Por último, la Corte Constitucional ha desarrollado la práctica de proferir órdenes o reglamentos generales y abstractos en las sentencias de tutela (en adelante reglamentaciones jurisprudenciales). En la sentencia T-970 de 2014 se planteó un caso en que un ciudadano solicitó a su clínica la realización de un "procedimiento para morir dignamente". No obstante, en esa ocasión la Corte Constitucional no podía realizar órdenes concretas porque el ciudadano falleció. Sin embargo, la Corte Constitucional -argumentando la necesidad de regular estos casos- definió de forma general y abstracta los presupuestos para el procedimiento de muerte asistida. En efecto, en la sentencia T-970 de 2014 definió que pueden acceder al procedimiento de "muerte digna" quienes padezcan de una enfermedad que produzca dolores intensos y siempre que se acredite el consentimiento libre, informado e inequívoco. En la parte resolutiva de esa sentencia ordenó a diferentes órganos administrativos, disposiciones para

\footnotetext{
${ }^{36}$ En el Auto 071 de 2001 (M.P. Manuel José Cepeda Espinosa) estableció las condiciones para que la inaplicación de una norma por excepción de inconstitucionalidad tenga efectos inter pares: “a) Que la excepción de inconstitucionalidad resulte de la simple comparación de la norma inferior con la Constitución (..). b) Que la norma constitucional violada, según la interpretación sentada por la Corte Constitucional, defina de manera clara la regla jurídica que debe ser aplicada (...) c) Que la inconstitucionalidad pueda ser apreciada claramente, sin que sea necesario sopesar los hechos particulares del caso y, por lo tanto, la inconstitucionalidad no dependa de tales hechos (...) d) Que la norma inaplicada regule materias sobre las cuales la Corte Constitucional ha sido investida por la Constitución de una responsabilidad especial (...) e) Que la decisión haya sido adoptada por la Sala Plena de la Corte en cumplimiento de su función de unificar la jurisprudencia o haya sido reiterada por ella".
} 
la reglamentación de esos presupuestos ${ }^{37}$. Es decir que en este tipo de sentencias, existen, además del dispositivo o decisum de la sentencia, reglas de contenido general y abstracto (la reglamentación jurisprudencial).

En Resumen, en las sentencias de tutela ( $\mathrm{T}$ y SU), la Corte Constitucional hace uso de los siguientes poderes normativos:

1) La resolución inter-partes de un problema jurídico, caso en el cual el ejercicio del poder implica la creación de una norma individual y concreta.

2) La solución inter comunis de un problema jurídico; es decir, una norma que define la situación del conjunto de individuos respecto de los cuales una acción u omisión está, en consideración de la Corte Constitucional, violando sus derechos fundamentales. En los casos en que la Corte Constitucional ejerce este poder la norma resultante puede ser una norma general y abstracta o particular y concreta.

3) La definición inter pares de una situación cuando se declara la excepción de inconstitucionalidad en una sentencia de tutela de la Sala Plena de la Corte Constitucional (sentencias SU). En estas circunstancias, el ejercicio del poder implica la creación de una norma general y abstracta.

4) La expedición de reglamentaciones jurisprudenciales, es decir, la creación de un conjunto de reglas generales y abstractas que regulan situaciones que van más allá de la definición del problema jurídico de la sentencia.

\subsection{La ratio decidendi de las decisiones judiciales como poder normativo}

La explicación de los precedentes judiciales se ha desarrollado alrededor de la noción de ratio decidendi ${ }^{38}$. No obstante, esta noción es empleada en el discurso jurídico para hablar de diferentes cuestiones de las que, para los propósitos de este trabajo, es importante subrayar $\operatorname{dos}^{39}$. En un primer sentido, la ratio decidendi se emplea para referirse al argumento que resulta necesario

${ }^{37}$ Corte Constitucional, Sentencia T-970 de 2014, M.P. Luis Ernesto Vargas Silva, 15 de diciembre de 2014.

${ }^{38}$ En los sistemas jurídicos de tradición anglosajona, surgió la diferenciación entre dos partes de las sentencias: la ratio decidendi y el obiter dictum. La ratio decidendi, en el derecho norteamericano, es equivalente al holding, propio del derecho inglés. Por su parte, la expresión obiter es empleada por los juristas, acompañada de las acotaciones dicta (plural) o dictum (singular).

39 Sobre la explicación del concepto de ratio decidendi véase CHIASSONI (2012) y TWINING y Miers (1991). 
para la justificación racional de la decisión judicial, y que, por tanto, otorga unidad a la relación entre el problema jurídico y la parte resolutiva. En otras palabras, el primer sentido de ratio decidendi corresponde a la premisa general que sirva de fundamento a la conclusión de la sentencia, la que puede o no coincidir con el derecho preexistente a la decisión. Como se observó en la primera parte de este trabajo, cuando esa premisa (esto es la ratio decidendi) no coincide con el derecho preexistente, entonces los jueces tienen el poder normativo de crearla.

En un segundo sentido, la ratio decidendi se refiere a la norma jurídica que, en el proceso de justificación de una decisión judicial (o de un conjunto de ellas) fue creada por el juez (o jueces) y que en virtud de la regla de precedente, debe ser seguida por los operadores jurídicos en casos posteriores. A pesar de que existe una evidente relación entre los dos sentidos de ratio decidendi, debe resaltarse que no toda ratio decidendi (en el primer sentido) corresponde a la creación de normas jurídicas generales y, por tanto, no es constitutiva de ratio decidendi en el segundo sentido. En efecto, en muchas sentencias judiciales el contenido de la ratio decidendi corresponde a lo previamente establecido en el derecho vigente. Además, no todas las ratio decidendi (en el primer sentido) son constitutivas de precedentes (i.e. no todas las sentencias tienen la capacidad de crear ratio decidendi en el segundo sentido). Para que los jueces puedan crear ratio decidendi en el segundo sentido, el ordenamiento jurídico debe reconocer la regla de precedente vinculante (i.e. establecer que la ratio decidendi es obligatoria).

Es en el segundo sentido de ratio decidendi el que constituye el precedente judicial. Es así como la Corte Constitucional ha reiterado que la ratio decidendi, bien sea de sus sentencias de constitucionalidad abstracta o de constitucionalidad concreta, obligan a los diferentes operadores jurídicos, y dentro de ellos a los jueces ${ }^{40}$. No obstante, en torno a esta noción persisten una serie de dudas ${ }^{41}:$ ¿Qué tipo de razones jurídicas genera una ratio decidendi?; ¿Cuáles son los criterios que deben ser tenidos en cuenta para la identificación de la ratio decidendi? ¿Cuál es la relevancia de los términos empleados en las providencias judiciales? Al respecto, se han propuesto tres modelos acera de

\footnotetext{
${ }^{40}$ Véase Sentencia T-292 de 2006, M.P. Manuel José Cepeda, 6 de abril de 2006 y Sentencia C-335 de 2008, M.P. Humberto Sierra Porto, 16 de abril de 2008.

${ }^{41}$ No sobra advertir que la discusión sobre la conceptualización de la ratio decidendi continúa abierta, incluso en el derecho anglosajón, ver: MarShall (1997), pp. 503-517; MacCormick y Summers (1997), pp. 503-517; Levenbook (2000), pp. 185-240 y Schauer (2004).
} 
la forma como funciona la ratio decidendi: el modelo natural, el modelo de resultados y el modelo de reglas ${ }^{42}$.

El modelo natural (o de principios) sostiene que la ratio decidendi está constituida por las razones morales (los principios) que justifican las decisiones. Según esto, en la ratio decidendi el juez articula razones o principios morales que son los que en definitiva constituyen el precedente ${ }^{43}$. Por otro lado, el modelo de reglas entiende que la ratio decidendi está constituida por las reglas jurídicas construidas en sentencias judiciales anteriores para justificar las decisiones. Según este modelo, los precedentes judiciales son reglas jurídicas que no dependen (i.e. se independizan) de las razones que justifican las decisiones judiciales ${ }^{44}$. Por último, el modelo de resultados propone que el hecho de que una decisión judicial haya tomado en determinado sentido, es constitutivo de una razón para decidir de la misma manera los casos futuros. Este modelo sostiene, en definitiva, que el seguimiento de precedentes se limita a la comparación del caso precedente con el actual, a fin de establecer si son similares en sus aspectos desde el punto de vista normativo. Sólo cuando, en efecto, los casos sean similares, existe el deber de seguir la ratio decidendi ${ }^{45}$.

En relación con estos modelos de ratio decidendi, deben hacerse tres observaciones. En primer lugar, resulta problemático concebir el modelo de resultados como un modelo independiente de los modelos de reglas y natural. En efecto, la operación de comparar hechos depende de la definición de los criterios (reglas o principios) que le sirven de fundamento para calificarlos como relevantes o irrelevantes. En otras palabras, para concluir que los hechos del caso precedente son o no similares al caso actual, es necesario recurrir a un parámetro normativo independiente de los hechos. Pero ese parámetro o bien corresponde a la formulación de las reglas disponibles en las providencias judiciales precedentes (i.e. la explicación de la forma como operan los precedentes corresponde al modelo de reglas); o bien a los principios que justifican la solución del caso (i.e. la explicación de los precedentes corresponde al modelo natural).

En segundo lugar la definición del modelo de ratio decidendi es una cuestión contingente, al depender de cómo la regla de precedente se implementa

${ }^{42}$ La formulación y explicación de estos modelos puede verse en: AlEXANDER (1989), pp. 1-64; AlEXANDER (2012), pp. 75-82; Alexander y Sherwin (2004), p. 15; Lamond (2005), pp. 1-26, y Lamond (2006), Chiassoni (2012), pp. 18-19.

43 AleXander (2012), p. 75.

${ }^{44}$ Alexander (2012), p. 76.

45 Alexander (2012), pp. 75-76. 
en cada ordenamiento jurídico ${ }^{46}$. En el caso del ordenamiento jurídico colombiano, la ratio decidendi se ha concebido principalmente desde el modelo de reglas. Para la Corte Constitucional "la ratio es asimilable al contenido de regla que implica, en sí misma, una autorización, una prohibición o una orden derivada de la Constitución" 47 . En palabras de la Corte Constitucional, la ratio decidendi "corresponde a la regla que aplica el juez en el caso concreto" que "se determina a través del problema jurídico que analiza la Corte en relación con los hechos del caso concreto y al ser una regla debe ser seguida en todos los casos que se subsuman en la hipótesis prevista en ella"48. En suma, de acuerdo con la Corte Constitucional la ratio decidendi de sus precedentes está constituida por la regla que ha creado para definir cómo resolver los problemas jurídicos. Veamos un ejemplo:

En la sentencia SU-250 de 1998 se definió que se violan los derechos al debido proceso y a la defensa de un notario desvinculado sin motivación alguna. Luego, en la sentencia T-800 de 1998, la Corte Constitucional resolvió que no se puede desvincular sin motivación a una auxiliar de enfermería y definió que está prohibido desvincular a un "empleado con la misma discrecionalidad con que puede hacerlo sobre uno de libre nombramiento y remoción, a menos que exista justa causa para ello". En la Sentencia C-734 se reiteró que "la desvinculación de los funcionarios de libre nombramiento y remoción no requiere de motivación" a diferencia de los cargos de carrera administrativa en los que, aun en los caos de provisionalidad, "la discrecionalidad se restringe". Posteriormente, en la Sentencia T-610 de 2003, la Corte Constitucional tuteló la situación de la empleada provisional de un hospital definiendo que "la motivación de un acto administrativo se consagra como una garantía para el administrado". Una vez consolidado ese precedente, la Corte Constitucional ha aplicado de forma consistente la siguiente regla: "la motivación de los actos de desvinculación de cargos de carrera ocupados en provisionalidad es indispensable -so pena de vulnerar el debido

\footnotetext{
${ }^{46}$ lincluso, algunos autores, recientemente, han observado que el modelo adoptado depende de los compromisos normativos adquiridos en el reconocimiento y la justificación de la doctrina de precedente Komarek (2013), pp. 49-171; Tiersma (2013), pp. 1187-1278.

${ }^{47}$ Corte Constitucional, Sentencia T-292 de 2006, M.P. Manuel José Cepeda, 6 de abril de 2006.

${ }^{48}$ Esta definición de ratio decidendi ha sido empleada por la Corte Constitucional en las sentencias, T-170 de 2015, M.P. Jorge Ignacio Pretelt, 15 de abril de 2015; T-292 de 2006, M.P. Manuel José Cepeda, 6 de abril de 2006, T-217 de 2013, M.P. Alexei Julio Estarada, 17 de abril de 2013.
} 
proceso-, pues éstos no se equiparan a funcionarios de libre nombramiento y remoción" 49 .

En tercer lugar, el ejercicio del poder normativo es mayor en los contextos en que se adopta el modelo de reglas. Esto es así porque cuando la ratio decidendi se concibe como principio, lo que resulta normativamente relevante es la identificación de la razón subyacente (la que, por cierto, no es creada por el juez) a la decisión judicial que constituye el precedente. En este caso, lo que hace el juez en el precedente es evidenciar la existencia de un principio (independiente de sus poderes normativos) y articular una forma específica de aplicarlo. En cambio, si la ratio decidendi es entendida como una regla, el juez que crea el precedente ha ejercido realmente sus poderes normativos porque lo que hace su ratio decidendi es definir cómo resolver una serie de casos de forma independiente a las normas y principios preexistentes.

\section{Conclusiones}

Las teorías del precedente judicial deben ser capaces de explicar los diferentes poderes normativos de los jueces en general (y de los tribunales constitucionales en particular). Sin esta explicación no es posible realizar un adecuado estudio de las características conceptuales, justificactorias, metodológicas e institucionales en las que se desarrolla la regla de precedente en los ordenamientos jurídicos actuales.

En este artículo se precisaron los diferentes poderes normativos de los que se vale la Corte Constitucional para la creación de normas jurídicas (véase tabla 2). En las sentencias de constitucionalidad abstracta ejerce un complejo poder normativo para definir asuntos de forma general y abstracta, al declarar, con efectos erga omnes, la constitucionalidad o inconstitucionalidad de las normas jurídicas. En esas sentencias también define contenidos normativos generales y abstractos cuando condiciona la constitucionalidad de una norma jurídica. En las sentencias de tutela, la Corte Constitucional puede crear normas particulares y concretas en el decisum de las sentencias de tutela. Pero también ejerce un poder normativo general y abstracto cuando, en sentencias de tutela, expide reglamentaciones jurisprudenciales y cuando declara los efectos inter pares. Por último, la Corte Constitucional también emplea la ratio decidendi de su sentencias para ejercer un poder normativo general y abstracto (por cierto que este poder, como se dijo, es mucho más robusto si, como ocurre en el derecho colombiano, se adopta el modelo de reglas).

${ }^{49}$ En la sentencia T-916 de 2013, M.P. Mauricio González Cuervo, 3 de diciembre de 2013, la Corte Constitucional muestra como esa regla ha sido reiteradamente aplicada. 
Tabla 2: poderes normativos de la Corte Constitucional

\begin{tabular}{|l|l|l|}
\hline Tipo de sentencia & Poder normativo & Tipo de norma \\
\hline Sentencia "C" & Cosa juzgada erga omnes & Generales y abstractas \\
\hline Sentencia "C" & Condicionamientos & Generales y abstractas \\
\hline Sentencias "T" y "SU" & Cosa juzgada inter partes & Individuales y concretas \\
\hline Sentencias "T" y "SU" & Cosa juzgada inter comunis & $\begin{array}{l}\text { Individuales y concretas/ } \\
\text { generales y abstractas }\end{array}$ \\
\hline Sentencias "T" y "SU" & $\begin{array}{l}\text { Reglamentos jurispruden- } \\
\text { ciales }\end{array}$ & Generales y abstractas \\
\hline $\begin{array}{l}\text { Sentencias "C", "T" y } \\
\text { "SU" }\end{array}$ & $\begin{array}{l}\text { Ratio decidendi (modelo de } \\
\text { reglas) }\end{array}$ & Generales y abstractas \\
\hline
\end{tabular}

Los resultados de este artículo plantean diferentes cuestionamientos. Toda vez que la Corte Constitucional ejerce poderes normativos de creación, modificación o derogación de normas jurídicas generales y abstractas, que exceden la nación de ratio decidendi, entonces las explicaciones que han limitado la explicación de la regla de precedente al estudio de la ratio decidendi de las sentencias del tribunal constitucional, tienen una insuficiente capacidad explicativa y justificativa.

Por otro lado, surgen dudas en relación con la validez del ejercicio de los poderes normativos (y por tanto de las normas creadas). Como se dijo, la validez de estas normas depende de que se pueda justificar su existencia en una norma de competencia que otorgue poder al sujeto (en este caso la Corte Constitucional) que lo ejerce. Sin embargo, es necesario cuestionarse acerca de la justificación y existencia de las normas de competencia que otorgan poderes a los tribunales constitucionales (y en especial de la forma en que ese poder ha sido ejercido por la Corte Constitucional colombiana) para definir reglas generales y abstractas. Otro cuestionamiento se refiere al fundamento del poder de la Corte Constitucional de crear normas generales y abstractas, mediante reglamentaciones jurisprudenciales en sentencias de tutela. En efecto, los argumentos que suelen ser expuestos sobre la justificación de los poderes normativos de la Corte Constitucional (v. gr, su posición como órgano de cierre de la jurisdicción constitucional, la certeza del derecho o el derecho a la igualdad) no son suficientes para justificar todos los poderes normativos señalados en este artículo.

Asimismo, se debe tener en cuenta que los modelos de creación judicial de normas jurídicas generales y abstractas, están relacionados con ideales acerca de la justificación de las autoridades judiciales. Estos ideales se relacionan a su vez con consideraciones acerca de los límites de los poderes normativos de los jueces. De esta manera, si como ocurre en el caso colombiano, estos ideales y modelos se entremezclan, los límites implícitos en cada uno de los modelos se 
pierden en la fusión. Esta multiplicidad de poderes hace que las metodologías de identificación del derecho judicial que pretenden reducirlo a, por ejemplo, la reconstrucción de líneas jurisprudenciales, resulten inadecuadas por dos razones: Primero, porque reducen el problema del derecho judicial a la identificación de la ratio decidendi. Segundo, porque asumen que la reconstrucción de la ratio decidendi de las decisiones judiciales debe hacerse desde el modelo common law.

Existen, por último, desafíos relacionados con la adecuada caracterización de la ratio decidendi en tanto norma jurídica. En particular, se debe dar cuenta del modelo de creación normativa (common law o legislativo) y del modelo de norma jurídica (reglas o principios). Para ello resulta de especial importancia comprender en qué sentido se relacionan los precedentes judiciales y las formulaciones lingüísticas que aparecen en las decisiones judiciales. En otras palabras, se debe explicar la distinción de la ratio decidendi como disposición normativa y como norma jurídica en estricto sentido. Esta explicación resultará fundamental, en particular, para elucidar la forma en que se deben interpretar los precedentes judiciales, y en general, para una adecuada implementación de la regla de precedente en el derecho constitucional.

\section{BiBLIOGRAFÍA CITADA}

Aguilo, Josep (2015): "Las fuentes del derecho", en: Abra Zamora, J. y Rodríguez Blanco, V., Enciclopedia de Filosofía y Teoría del Derecho. Volumen II (Stuttgart, Nomos), pp. 1019-1066.

AlCHOURRÓN, Carlos y BuLYGIN, Eugenio (1987): Introducción a la metodología de las ciencias jurídicas y sociales (Buenos Aires, Astrea).

AleXAnder, L. George (1989): "Constrained by Precedent", en: Southern California Law Review (63), pp. 1-64.

(2012): "Precedential Constraint, Its Scope and Strength: A Brief Survey of the Possibilities and Their Merits", en: Pulido, Carlos y Bustamante, T., On the Philosophy of Precedent (Stuttgart: Nomos), pp. 75-82.

Alexander, L. George y Sherwin, Emily (2004): "Judges as Rulemakers", en: University of San Diego Public Law and Legal Theory Research Paper Series. (No 15), pp. 1-35. Consultado el 12 de marzo de 2017 Disponible en: http://digital.sandiego.edu/cgi/viewcontent.cgi?article=1023\&context=lwps_public.

ATRIA, Fernando (2005): Lagunas en el Derecho (Madrid, Marcial Pons).

Bernal Pulido, Carlos (2008): "El precedente en Colombia", en: Revista Derecho del Estado ( N 21$)$, pp. 1-14. 
Bulygin, Eugenio (2003): "Los jueces ¿crean derecho?", en: Isonomía ( $\left.N^{0} 18\right)$, pp. 7-25.

2005): "Creación y aplicación del derecho", en: Atria F., Bulygin E., Moreso J., Navarro P., Rodríguez J. y Ruiz Manero J. Lagunas en el derecho (Madrid: Marcial Pons), pp. 29-44.

Carrió, Genaro (1990): Notas sobre derecho y lenguaje (Buenos Aires, LexisNexis, Abeledo-Perrot).

Castillo Córdoba, Luis (2016): Los precedentes vinculantes del Tribunal Constitucional (Lima, Ed. Gaceta Jurídica).

Chiassoni, Pierlugini (2012): "The Philosophy of Precedent: Conceptual Analysis and Rational Reconstruction", en: Bernal Pulido, C. y Bustamante, T., On the Philosophy of Precedent. (Stuttgart: Nomos), pp. 18-19.

Cross, Rupert y Harris, J. W. (2012): El precedente en el derecho inglés (Madrid, Marcial Pons).

Cueto RúA, Julio César (1997): El Common Law (Buenos Aires, Abeledo-Perrot).

DíAz Revorıo, Francisco J. (2000): "Interpretación constitucional y sentencias interpretativas", en Repertorio Aranzadi del Tribunal Constitucional ( $N^{\circ} 1$ ), 1799-1824.

DwOrkIN, Ronald (1975): "Hard Cases", en: Harvard Law Review (No 88), pp. 1057-1109.

Garay, Alberto (2013): La doctrina del precedente en la Corte Suprema (Buenos Aires, Abeledo Perrot).

Hart, H. L. (1994): The concept of law. (Ed. Penelope A. Bulloch and Joseph Raz, Oxford, Clarendon Press).

Hohfeld, Wesley Newcomb (1991): Conceptos jurídicos fundamentales (Traducc. Genaro Carrió. México D.F., Fontamara).

Kelsen, Hans (1982): Teoría pura del derecho. (Traducc. Roberto J. Vernengo. UNAM, Instituto de Investigaciones Jurídicas).

KOMAREK, Jan (2013): "Reasoning with previous decisions: beyond the doctrine of precedent", en: American Journal of Comparative Law ( $\mathrm{N}^{\circ}$ 61), pp. 149-171.

Lamond, Grant (2005): "Precedents Create Rules?", en: Legal Theory ( $\left.N^{0} 11\right)$, pp. 1-26.

(2006): "Precedent and Analogy in Legal Reasoning", en: E. Zalta, ed., The Stanford Encyclopedia of Philosophy. Consultado el 16 de marzo de 2016. Disponible en: http://plato.stanford.edu/archives/spr2014/entries/ legal-reas-prec/. 
LANCHEROS, Juan (2012): El precedente constitucional en Colombia y su estructura argumentativa. Síntesis de las experiencias de un sistema de control mixto de constitucionalidad a la luz de la sentencia T-292 de 2006 de la Corte Constitucional en Dikaion (№ 21), pp. 159-186.

LevenBook, Barbara (2000): "The Meaning of a Precedent", en: Legal Theory ( $\left.\mathrm{N}^{\circ} 6\right)$, pp. 185-240.

Levl, Edward (1948): "An Introduction to Legal Reasoning", en: University of Chicago Law Review (№ 15), pp. 501-574.

LóPEZ, Diego (2006): El derecho de los jueces (Bogotá, Legis). (2016): Eslabones del derecho (Bogotá, Legis).

MacCormick, Neil y Summers, Robert (1997): "Apendix", en: MacCormick, N. y Summers, R. Interpreting Precedents. (Aldershot: Ashgate/Dartmouth), pp. 559-561.

MAGALONI, Ana (2001). El precedente constitucional en el sistema norteamericano. (Madrid: McGraw-Hill).

Marshall, Geoffrey (1997): "What is binding in a precedent", en: MacCormick, N. y Summers, R., Interpreting Precedents (Aldershot: Ashgate/Dartmouth), pp. 503-517.

Navarro, Pablo y Rodríguez, Jorge (2014): Deontic Logic and Legal Systems (New York: Cambridge University Press).

Nogueira, Humberto (2010): "La sentencia del Tribunal Constitucional en Chile: análisis y reflexiones jurídicas", en: Estudios Constitucionales (Volumen 8, $\mathrm{N}^{\circ} 1$ 1), pp. 79-116.

Olano, Hernán (2004): "Tipología de nuestras sentencias Constitucionales", en: Vniversitas ( $\left.\mathrm{N}^{\circ} 108\right)$, pp. 571-602.

Pulido, Fabio (2018): Jueces y Reglas. La autoridad del precedente judicial (Bogotá, Universidad de La Sabana).

QUiNCHE, Manuel (2014): El precedente judicial y sus reglas (Bogotá, Legis).

Raz, Joseph (1990): Practical Reason and Norms (Oxford, Oxford University Press).

RodríGuez, Joseph (2003): "Naturaleza y lógica de las proposiciones normativas: contribución en homenaje a G.H. von Wright", en: Doxa: Cuadernos de Filosofía del Derecho (№ 26), pp. 87-109.

SAGÜES, Néstor (2006): "La eficacia vinculante de la jurisprudencia de la corte suprema de justicia en EE.UU. y Argentina", en: Estudios Constitucionales ( No 4), pp. 17-32. 
SCHAUER, Frederick (2004): Las reglas en juego. Un examen filosófico de la toma de decisiones basada en reglas en el derecho y en la vida cotidiana (Barcelona: Marcial Pons).

SHAPIRO, Scott J., and RIPSTEIN, Arthur (2007): “The 'Hart-Dworkin' Debate: A Short Guide for the Perplexed", en: Ronald Dworkin. Contemporary Philosophy in Focus (Cambridge: Cambridge University Press), pp. 22-55.

SierRA, David (2016): "El precedente: un concepto", en: Revista Derecho del Estado (No 36), pp. 249-269.

Tiersma, Peter (2013): "The Textualization of Precedent", en: Notre Dame L. Rev ( $\left.\mathrm{N}^{\mathrm{o}} 82(3)\right)$, pp. 1187-1278.

TwinING, William y Miers, David (1991): How to do Things with Rules (Londres, Weidenfeld and Nicolson).

\section{JURISPRUDENCIA CITADA}

Auto 207 de 2010, Corte Constitucional, M.P Luis Ernesto Vargas.

Auto 071 de 2001, Corte Constitucional, M.P. Manuel José Cepeda Espinosa.

Sentencia C-149 de 1993, Corte Constitucional, M.P. José Gregorio Hernández. Sentencia C-037 de 1996, Corte Constitucional, M.P. Vladimiro Naranjo Mesa. Sentencia T-290 de 1996, Corte Constitucional, M.P. Jorge Arango Mejia.

Sentencia C-737 de 2001, Corte Constitucional, M.P. Eduardo Montealegre Lynett.

Sentencia C-774 de 2001, Corte Constitucional, M.P. Rodrigo Escobar Gil.

Sentencia C-028 de 2006, Corte Constitucional, M.P. Humberto Antonio Sierra Porto.

Sentencia T-292 de 2006, Corte Constitucional, M.P. Manuel José Cepeda. Sentencia T-583 de 2006, Corte Constitucional, M.P. Marco Gerardo Monroy. Sentencia C-335 de 2008, Corte Constitucional, M.P. Humberto Sierra Porto. Sentencia SU-913 de 2009, Corte Constitucional, M.P. Juan Carlos Henao. Sentencia C-393 de 2011, Corte Constitucional, M.P. María Victoria Calle. Sentencia T-217 de 2013, Corte Constitucional, M.P. Alexei Julio Estarada. Sentencia C-332 de 2013, Corte Constitucional, M.P. Mauricio González Cuervo. Sentencia T-916 de 2013, Corte Constitucional, M.P. Mauricio González Cuervo. Sentencia T-970 de 2014, Corte Constitucional, M.P. Luis Ernesto Vargas Silva. Sentencia T-170 de 2015, Corte Constitucional, M.P. Jorge Ignacio Pretelt. 
Sentencia SU-230 de 2015, Corte Constitucional, M.P. Jorge Ignacio Pretelt. Sentencia C-259 de 2015, Corte Constitucional, M.P. Gloria Stella Ortiz Delgado. Sentencia C-007 de 2016, Corte Constitucional. M.P. Alejandro Linares. Sentencia C-223 de 2017, Corte Constitucional, M.P. Alberto Rojas Ríos. 